\section{ARTICLE}

Dominic Webber, Tullio Buccellato and Sean White

\section{Office for National Statistics}

\title{
The global recession and its impact on tourists' spending in the UK
}

\section{Introduction}

This article uses an input-output (IO) modelling approach to investigate the impact of the global recession on the expenditures of inbound and overnight domestic visitors and the wider effect on the UK economy. The results suggest that the economic crisis has had a negative direct impact on tourism in the UK of around $£ 42$ million, although this was the relatively small difference between a large increase in domestic holiday tourism and falls in business and visiting family, friends and relatives spending. In turn, this led to a negative indirect impact of $\mathrm{f} 45$ million, representing a $\mathrm{f} 21$ million net fall across the production chain and a $\mathrm{f} 24$ million net fall in the compensation of employees. Overall, the economy has suffered a total net loss of $\mathrm{f} 87$ million.

\section{-} ourism is an important sector in the UK economy. Recent estimates show that in 2006 consumption by tourists accounted for 3.3 per cent of UK gross value added $(\mathrm{GVA})^{1}$. Furthermore, between 2000 and 2008 inbound tourism expenditure grew at an average rate of 3.3 per cent ${ }^{2}$ each year. However, this was a period of relatively strong economic growth in the UK and the rest of the world. Since then the UK has endured its largest post war recession as the major economies around the world entered into a synchronised downturn, the effects of which have been felt by the tourism sector in the UK and globally.

It is easy to understand why tourism may be particularly adversely affected by a global economic downturn. Household consumption, both at home and overseas, has been hit by falling asset values, rising unemployment and tightening of credit conditions. Business expenditure, which is a major component of tourism spending, has fallen in line with economic activity and as firms seek to reduce costs and preserve cash flows. With household and corporate sectors looking to rebuild balance sheets the more discretionary components of spending are those most likely to face retrenchment.

However, the net effects on tourism spending in the UK are not immediately obvious. For example, the weakened economic position of households and firms may induce substitution from outbound to domestic tourism, an observation coined as the staycation effect. Staycation effects are likely to have been supported by depreciation of sterling since the second half of 2008, making outward trips for domestic residents relatively more expensive compared to domestic ones.

Sterling depreciation also makes inbound tourism cheaper and more attractive to foreigners. Recent evidence from Consumer Trends ${ }^{3}$ has shown that net tourist spending has made a negative contribution to household consumption growth during the recession. This is also consistent with the findings reported in the Travel and tourism statistical bulletin ${ }^{4}$, which has shown that UK visits abroad have fallen more sharply than foreign visits to the UK.

This article attempts to answer two questions relating to tourism and the economic downturn. First, how has the economic downturn affected the expenditures of domestic and inbound visitors? Second, what is the overall economic impact of this?

The next section assesses the direct change in expenditure of inbound and domestic tourists over the recession. Then, the third section uses input-output modelling ${ }^{5}$ to calculate the overall economic impact of the direct changes in expenditure induced by the recession. Finally some conclusions are offered. The technical details on the methodologies adopted are presented in an Appendix.

\section{The direct effects of the recession on tourism expenditure}

This section estimates the change in expenditure on two of the main 
components of the UK tourism sector ${ }^{6}$ - inbound and domestic overnight visitors. The second of these is one of three components that make up total domestic tourism. Excursionists and resident visitors travelling abroad make up the remainder. The expenditure of resident visitors travelling abroad captures the amount that domestic residents spend in the UK as a consequence of an outbound trip. It consists of fares for UK-based outbound carriers. This data is not centrally collected on an annual, let alone quarterly basis. Similarly, day-visitor or excursionist data is sparse with the latest survey conducted for England in 2005. Consequently the only element of domestic tourism which will be considered in this study is overnight visitors. Data on these visitors are obtained by the UK Tourism Survey (UKTS), conducted by Taylor Nelson Sofres (TNS). This provides quarterly expenditure by purpose of visit, which is broken down into purchased products.

ONS measures the expenditure of inbound visitors through the International Passenger Survey (IPS). It provides monthly data on the expenditure of these visitors, one month after the reference period.

Expenditure by purpose of trip is further categorized by the product purchased. This is required to apportion expenditure to its supplying industry ${ }^{7}$ which is done in two stages. The first involves disaggregating expenditure by product purchased, following the classification contained in the ONS' Supply and Use (SU) Tables, which disaggregates the economy into 123 products and industries. Expenditure breakdowns are available both for the IPS and the UKTS. However, they are not without weaknesses. For instance, the IPS expenditure trailer, while being detailed, only covers the year 1997 . This is a major drawback as using it assumes the composition of goods and services purchased by tourists have remained unchanged since then.

The UKTS, on the other hand, provides an expenditure breakdown for every quarter, and by purpose of visit. A cautionary note should be added, however, that when one starts considering expenditure broken down in this way, the sample size is much reduced.

The second stage of apportioning the purchased product to its supplying industry requires the use of a Make Matrix, the technical details of which are described in Box 1.

Figure 1 shows the four-quarter change in nominal expenditure for inbound visitors. Changes in spending over the period have been fairly volatile. Inbound holiday tourism, although dipping in 2008 Q3 has shown fairly constant growth over time, and increased growth over the last few quarters. Business tourism on the other hand, has generally shown negative changes, apart from in 2008 Q2 and 2008 Q4. Visiting friends and relatives (VFR), and miscellaneous ${ }^{8}$ tourism have both fluctuated over time. VFR exhibits a small positive total increase, whilst the opposite is true for the miscellaneous part of spending.

Figure 2 shows the change in expenditure of domestic overnight tourists. It shows that the latter part of 2008 and early 2009 was characterised by falls in domestic tourism spending. However, since then domestic tourism expenditure has shown two quarters of stronger growth, predominately accounted for by increases in domestic holiday tourism. Domestic business tourism, despite showing positive change in 2008 Q2, recorded a negative change throughout the whole period considered. Domestic VFR shows a fairly cyclical trend over the period, with the overall net spending effect being quite neutral.

Latest National Accounts data show that UK gross domestic product (GDP) fell for six successive quarters from 2008 Q2 to 2009 Q3 and the 6.4 per cent peak-to-trough fall was the largest since the start of the data in 1955. However, tourists' spending by its very nature is not just determined by domestic economic conditions but also by those overseas. Therefore, cyclical activity in the UK tourist industry need not exactly follow the rest of the economy. Indeed, analysis of Figures 1 and 2 suggest there is a quarter lag between the start of the UK recession and the change in inbound and domestic overnight tourism expenditure. As a result, this article uses the period 2008 Q3 to 2009Q3 as its scope for analysis.

Table 1 presents the total change in tourists' direct expenditure over the period 2008 Q3 to 2009 Q3 and how this has been accounted for by different supplying industries. For clarity, industries have been grouped into sectors, in line with the SU table methodology. Tourism though, in contrast to the SU tables, is a sector in its own right made up of a set of industries as recommended by international guidelines on tourism statistics ${ }^{9}$. The table shows there has been a decline in expenditure of inbound and domestic overnight tourists of $£ 42$ million. Inbound tourism expenditure has increased by $£ 142$ million, while domestic tourism has fallen by $£ 184$ million.

The main driver of the increase in inbound tourism is holiday visitors, which increased by $£ 677$ million. However, this is almost completely offset by a decrease of $£ 668$ million in inbound business expenditure by foreign visitors. Foreign visitors to friends and relatives (VFR) and miscellaneous trips increased inbound tourist receipts by $£ 16$ million and $£ 117$ million respectively.

Changes in domestic overnight tourist spending have also shown offsetting patterns. Whilst domestic holiday tourism

\section{Box 1}

\section{Using the Make Matrix to apportion tourists' expenditure by supplying industry}

Survey data reports the changes in expenditure by inbound and domestic tourists by products purchased. Translating changes in the demand for a specific product to changes in output of the supplying industries requires the use of a Make Matrix. This article makes use of one constructed by the Stockholm Environment Institute for 2004. It details the output of each of the 123 industries in terms of 123 products. It is largely diagonal, as each product is chiefly produced by its corresponding industry; nonetheless, there exist off-diagonal elements to it.
For each type of visitor, and by purpose of visit, there is a 123product vector detailing the breakdown of products purchased. By applying this to information conveyed in the MM it is then possible to derive demand in terms of industry outputs as opposed to products purchased. This information is then required to derive the indirect and induced effects of the change in direct spending using the Input-Output method, which is explained in more detail in the Appendix. 


\section{Figure 1}

\section{Change in final demand of inbound tourists by purpose of trip, 2007 Q1 - 2009 Q3}



Source: International Passenger Survey, Stockholm Environment Institute

\section{Figure 2}

\section{Change in final demand of domestic tourists by purpose of trip, 2007 Q1 - 2009 Q3}

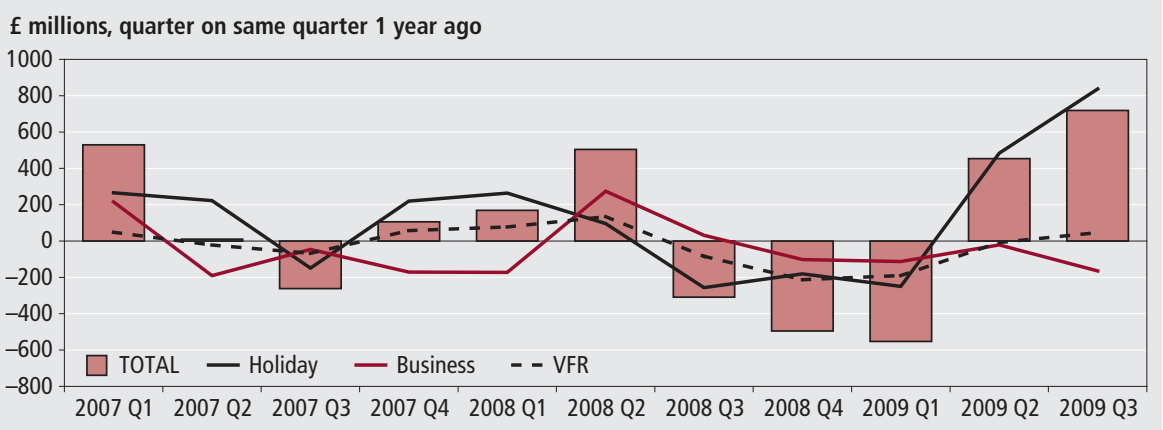

Source: United Kingdom Tourism Survey, Stockholm Environment Institute

grew strongly by $£ 633.1$ million, domestic business trip expenditure fell by $£ 368.9$ million and domestic VFR trips spending also fell by $£ 448.6$ million. The increase in domestic holiday tourism is indicative of the 'staycation' phenomena. Figure 3 plots the change in expenditure of outbound holiday visitors and domestic holiday visitors. It shows clearly that whilst outbound holiday visit expenditure has declined considerably since 2008 Q3, domestic holiday tourism expenditure has shown the opposite trend.

Figure 4 displays the change in demand of sector output demanded by both types of visitors (reflecting the data presented in Table 1). On balance, the effect on the tourism sector has been positive, showing an increase of $£ 51.4$ million in the demand of its products, mainly driven by inbound tourists. Although there has been an overall fall in the expenditure of tourists, the overall direct impact on the tourism sector has been positive. The sector which has suffered the most is the manufacturing sector followed by the wholesale and retail trade sector. They have experienced direct falls in spending of $£ 69.8$ million and $£ 38.1$ million respectively.

A note of caution should be applied at this stage. It is being assumed here that a fall in demand for manufactured goods, for example, of $£ 69.8 \mathrm{~m}$ is equal to the fall in that sector's output. This is not necessarily the case. For instance, as recorded prices are market prices there will be a fall in VAT and other indirect revenues to the government. Furthermore, if the good or service is imported then the fall in demand will be felt mainly by overseas producers. If these effects are significant then the estimated change in sector output from a change in final demand will be overestimated. Therefore, the overall economic impact of a change in final demand is likely to be overestimated, and the multiplier effect overstated. Throughout the rest of this paper it will be assumed that goods and services purchased in the UK are produced here. Furthermore, a decline in the demand for goods and services will be felt fully and equally by the industry that produces them. Future analysis will attempt to refine these rather strong assumptions.

The fall in demand for manufacturing sector output is driven by domestic tourists, who reported a drop of $£ 197$

Table 1

Total change in final demand of sector output by type of visitor and purpose of visit 2008 Q3 - 2009 Q3

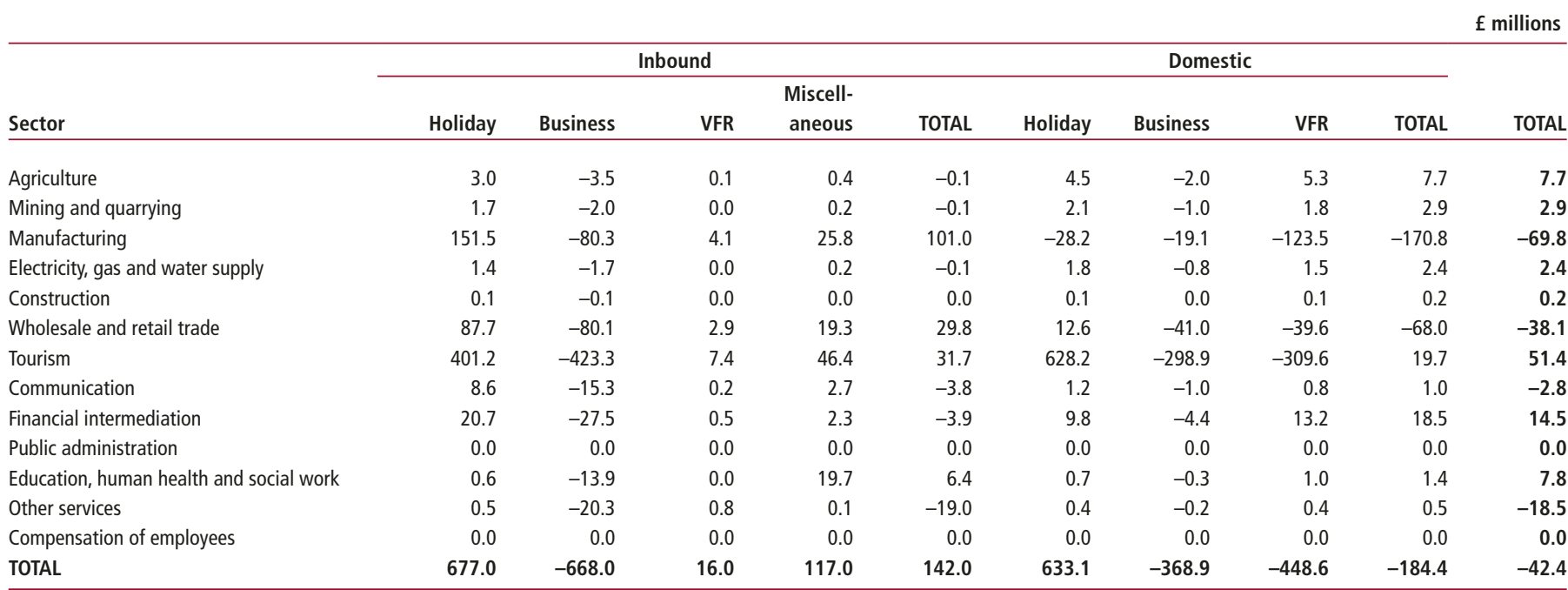




\section{Figure 3 \\ Change in final demand of outbound and domestic visitors for the purpose of holiday, 2007 Q1 - 2009 Q3}

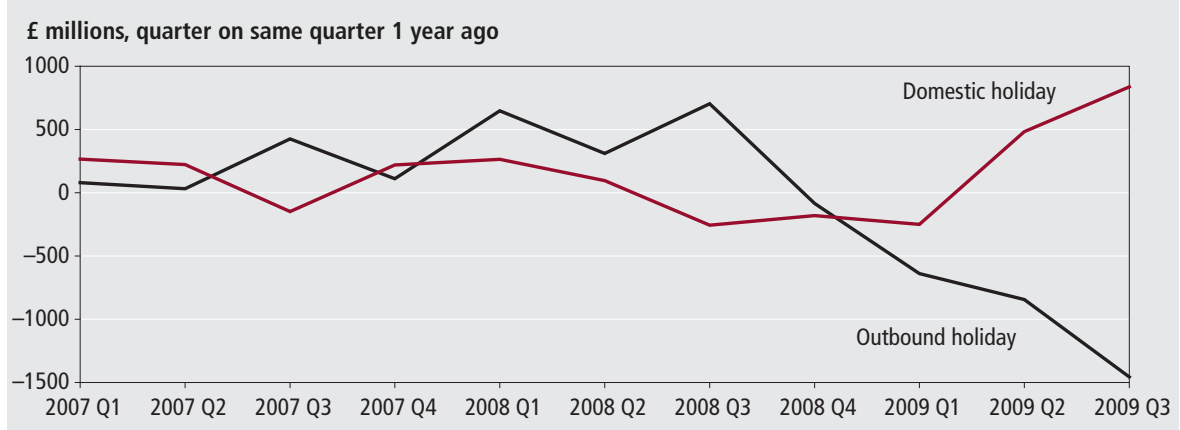

Source: International Passenger Survey, United Kingdom Tourism Survey

\section{Figure 4}

\section{Change in final demand of sector output by type of visitor, 2008 Q3 - 2009 Q3}

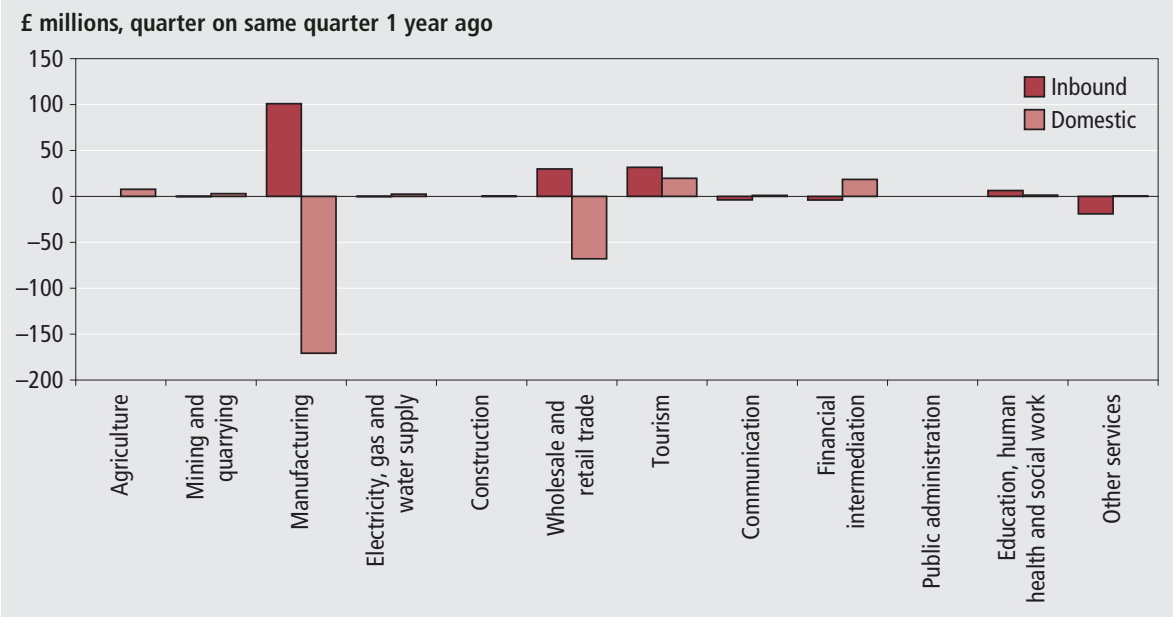

Source: International Passenger Survey, United Kingdom Tourism Survey, Stockholm Environment Institute

million in their expenditure on clothing (translated to a fall in 'Wearing apparel; dressing and dying of fur' in the IO table). This has been largely offset by the increase in inbound holiday visitors who spend almost 10 per cent of their total expenditure on manufactured goods, leading to an increase in spending of $£ 151.5$ million from manufacturing industries.

Similarly, domestic tourists have reported a drop in 'Other shopping' expenditure, translated to a $£ 156$ million fall in 'Retail trade, except of motor vehicles and motor cycles, repair of personal and household goods' in the IO tables. This mainly accounts for the relatively large fall in the spending on the output of the wholesale and retail trade sector.

\section{The indirect and induced effects}

This section quantifies the indirect, induced, and hence overall effect on the
UK economy resulting from the $£ 42$ million fall in the net expenditure of inbound and domestic overnight tourists. Indirect effects occur as the change in initial spending results in further rounds of purchases by industries in the supply chain of final products consumed by tourists. For example, if tourists demand extra hotel rooms, the hotel industry will purchase products which are used in the production of hotel rooms. This could be linen for bedding, food or toiletries. In turn, this will induce a further round of spending from each of these supplying industries.

Induced effects are the impacts on household income due to a change in the direct spending of tourists. This occurs through changes in labour requirements resulting from changes in industry output. The total change in output is simply derived as the summation of direct, indirect and induced effects. The process of quantifying the indirect and induced effects involves algebraic matrix manipulation, first proposed by Wassily Leontief ${ }^{10}$. The methodology and tables used are discussed in finer detail in the Appendix. Table 2 reports the indirect effects as a result of the changes in direct spending of tourists.

Overall, it is calculated there is a total negative indirect effect of $£ 20.6$ million. This is due to a negative contribution from domestic tourism of $£ 204$ million, but counteracted by inbound tourism which has a positive indirect impact of $£ 183.4$ million. The most striking result is that the tourism sector shows an indirect negative effect of $£ 172$ million, even though direct spending has increased by $£ 51$ million. The net result is that the output of the tourism sector over the period studied dropped by $£ 121$ million. The difference between the change in the direct and indirect effects are attributed to domestic tourists - in particular the VFR category of spending.

VFR spending, which has proportionately the highest indirect effects with respect to direct spending, has declined significantly, and been offset by spending from holiday/business visitors, with far lower indirect effects thus leading to negative indirect effects despite a small increase in gross direct spending. This effect occurs because the pattern of VFR spending is very different - clearly with accommodation sectors less dominant, and as Figure 5 illustrates the hotel and restaurant industry, as a proportion of its output, makes the least intra-sector purchases in the production of its products. The result being that a change in demand for hotel and restaurant products has little effect on the output of other tourism industries, compared to industries such as railway transport or travel agencies. This explains why the fall in output in the tourism sector driven by VFR visitors is not offset by the increase in spending in the tourism sector of holiday visitors.

The opposite pattern emerges for the change in indirect spending attributed to the manufacturing sector, which is $£ 161$ million, compared to a fall in direct spending of $£ 69.8$ million. In this case the difference reflects that the manufacturing sector is the most important contributor to the production of intermediate goods. So, although spend on its final demand goods has fallen, demand for the products that use its output in their production has increased, and hence it has seen an indirect boost to its output. 
Table 2

Total change in indirect effects on sector by type of visitor and purpose of visit, 2008 Q3 - 2009 Q3

f millions

\begin{tabular}{|c|c|c|c|c|c|c|c|c|c|c|}
\hline \multirow[b]{2}{*}{ Sector } & \multicolumn{5}{|c|}{ Inbound } & \multicolumn{4}{|c|}{ Domestic } & \multirow[b]{2}{*}{ TOTAL } \\
\hline & Holiday & Business & VFR & $\begin{array}{l}\text { Miscell- } \\
\text { aneous }\end{array}$ & TOTAL & Holiday & Business & VFR & TOTAL & \\
\hline Agriculture & 23.9 & -22.9 & 0.5 & 3.5 & 5.0 & 24.7 & -12.4 & 15.7 & 28.0 & 33.0 \\
\hline Mining and quarrying & 11.2 & -11.3 & 0.3 & 1.8 & 1.9 & 11.8 & -6.7 & -6.9 & -1.8 & 0.1 \\
\hline Manufacturing & 199.5 & -200.3 & 4.4 & 31.7 & 35.3 & 204.0 & -110.3 & 32.1 & 125.8 & 161.0 \\
\hline Electricity, gas and water supply & 31.2 & -30.4 & 0.7 & 5.4 & 6.9 & 28.1 & -16.4 & -12.4 & -0.7 & 6.1 \\
\hline Construction & 22.1 & -22.3 & 0.5 & 3.9 & 4.2 & 22.8 & -13.0 & -23.6 & -13.8 & -9.6 \\
\hline Wholesale and retail trade & 124.6 & -121.5 & 2.9 & 21.7 & 27.7 & 111.5 & -65.3 & -49.9 & -3.7 & 24.0 \\
\hline Tourism & 133.7 & -128.6 & 3.1 & 22.2 & 30.5 & 146.8 & -83.0 & -266.2 & -202.4 & -172.0 \\
\hline Communication & 32.7 & -34.0 & 0.8 & 5.5 & 5.0 & 33.5 & -18.5 & -14.8 & 0.2 & 5.2 \\
\hline Financial intermediation & 303.6 & -303.9 & 7.3 & 51.3 & 58.2 & 291.4 & -170.1 & -236.0 & -114.7 & -56.5 \\
\hline Public administration & 6.2 & -6.1 & 0.2 & 1.0 & 1.3 & 5.3 & -3.4 & -6.3 & -4.4 & -3.1 \\
\hline Education, human health and social work & 20.7 & -22.0 & 0.5 & 4.9 & 4.2 & 20.9 & -11.8 & -14.9 & -5.7 & -1.6 \\
\hline Other services & 19.6 & -19.9 & 0.5 & 3.2 & 3.3 & 21.9 & -11.4 & -21.3 & -10.7 & -7.4 \\
\hline TOTAL & 929.0 & -923.2 & 21.4 & 156.2 & 183.4 & 922.6 & -522.1 & -604.5 & -204.0 & -20.6 \\
\hline
\end{tabular}

Source: International Passenger Survey, United Kingdom Tourism Survey, Stockholm Environment Institute, Karen Turner's ESRC Leadership Fellow

\section{Figure 5}

\section{Share of each tourism industry's intermediate consumption supplied by other tourism industries, 2004}

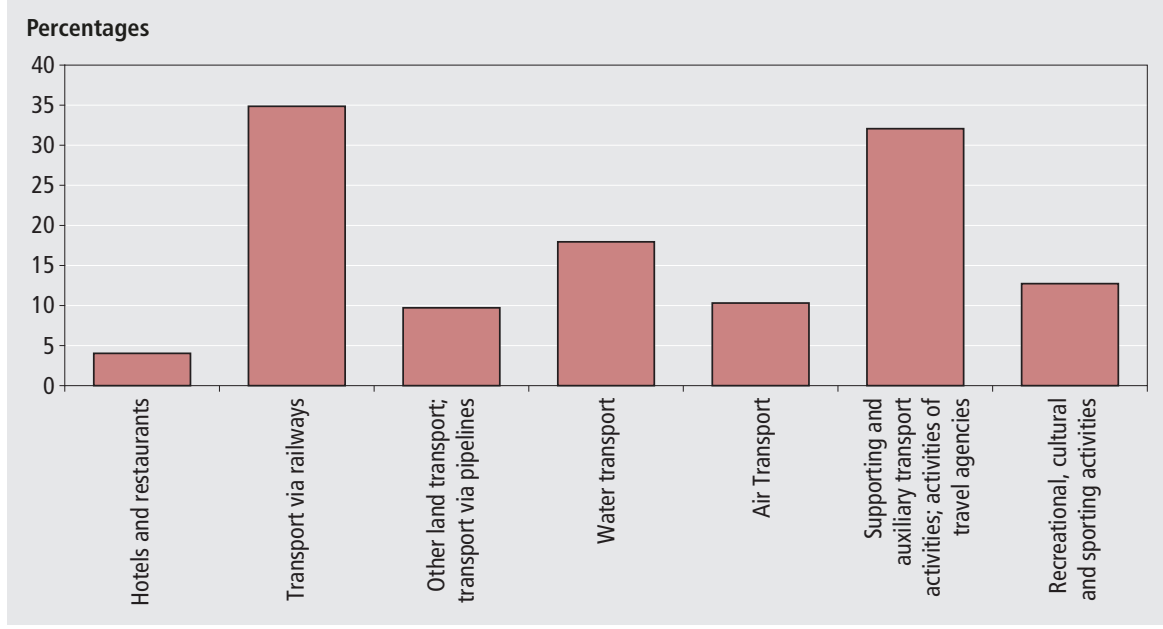

Source: Stockholm Environment Institute

Figure 6

Total absolute changes in indirect effects by sector, 2008 Q3 - 2009 Q3

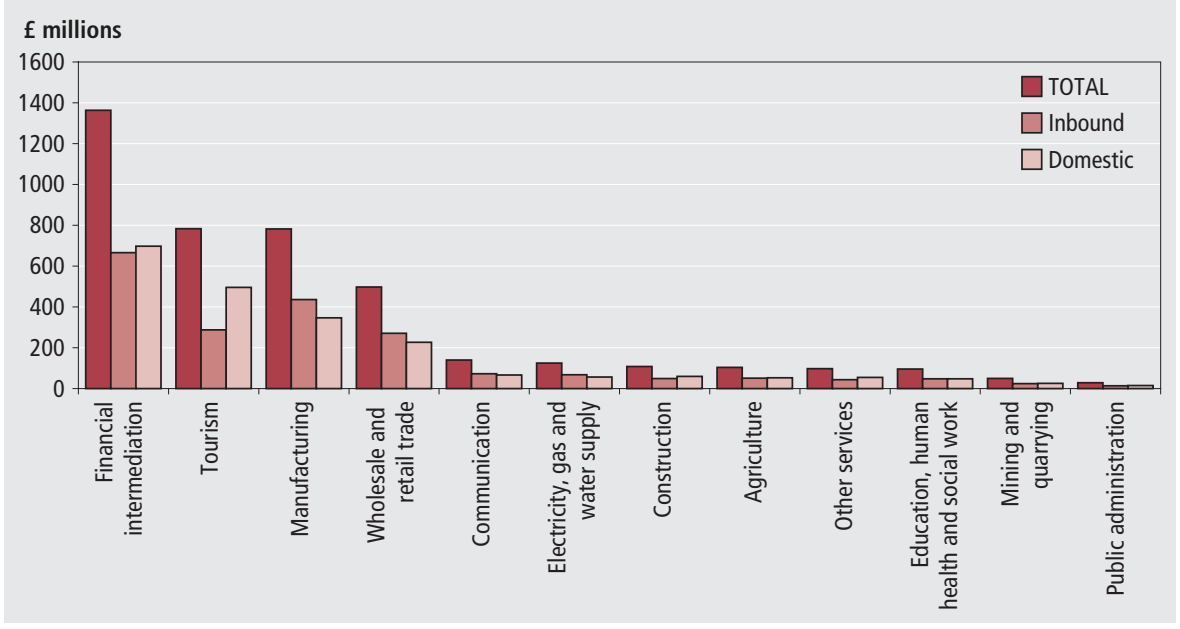

Source: International Passenger Survey, United Kingdom Tourism Survey, Stockholm Environment Institute, Karen Turner's ESRC Leadership Fellow
Figure 6 shows the total absolute changes in indirect spending by sector attributed to both inbound and domestic, in order to gain a better understanding of the significance of each sector in the production of products tourists purchase. The absolute change is reported for a simple reason. There are opposite trends exhibited by holiday and business visitors, with the former showing a large increase in indirect effects, and the latter showing a decrease. Therefore, they would cancel each other out when considering the total changes in indirect effects. For example, the financial intermediation sector shows the largest change in indirect effects in absolute terms. This reflects the fact that this sector plays an important role in the production of goods that tourists buy. However, in actual terms, holiday visitors are responsible for an indirect impact on the financial intermediation sector of $£ 303.6$ million, while business visitors account negatively for $£ 303.9$ million. Hence focussing on just the total actual (net) change could severely underestimate the importance of some sectors in the production processes.

Other sectors which are responsible for a relatively large change in indirect spending are wholesale and retail trade, and the tourism sector. The wholesale and retail trade provides the mechanism for which goods are sold. The fact that tourism ranks highly appears indicative of the existence of intra-industry links within the tourism sector. An obvious example of these links comes from the travel agency industry which will purchase hotel rooms, travel services and entertainment tickets to produce its own packaged good. This hypothesis 
Table 3

Total change in induced effects by type of visitor and purpose of visit, 2008 Q3 - 2009 Q3

f millions

\begin{tabular}{|c|c|c|c|c|c|c|c|c|c|c|}
\hline \multirow[b]{2}{*}{ Sector } & \multicolumn{5}{|c|}{ Inbound } & \multicolumn{4}{|c|}{ Domestic } & \multirow[b]{2}{*}{ TOTAL } \\
\hline & Holiday & Business & VFR & $\begin{array}{l}\text { Miscell- } \\
\text { aneous }\end{array}$ & TOTAL & Holiday & Business & VFR & TOTAL & \\
\hline Compensation of employees & 472.6 & -474.4 & 11.0 & 87.3 & 96.6 & 460.2 & -263.9 & -316.8 & -120.5 & -24.0 \\
\hline
\end{tabular}

Source: International Passenger Survey, United Kingdom Tourism Survey, Stockholm Environment Institute, Karen Turner's ESRC Leadership Fellow

is confirmed by the fact that the travel agency industry accounts for 44 per cent of the change in indirect effects of the tourism sector.

Table 3 presents the induced effects on household income due to a change in direct spending by tourists. The overall effect is negative in the region of $£ 24$ million. This is due to a $£ 96.6$ million positive impact from inbound visitors being overshadowed by the $£ 121$ million negative contribution of domestic visitors.

Finally, the derivation of indirect and induced effects allows the computation of a multiplier of direct spending to output. The total output to total spending multiplier for the period covered is found to be 2.1. This indicates that for every $\mathfrak{E} 1$ change in spend by tourists, there is a $£ 2.10$ change in overall economy output. This can be further disaggregated into indirect and induced multipliers -0.5 and 0.6 respectively. So every $£ 1$ spent by a tourist generates $50 \mathrm{p}$ in terms of additional rounds of spending on intermediate products, and 60p in the form of compensation of employees.

\section{Conclusion}

This article measures how key components of the UK tourism industry have performed in the light of the recent global economic downturn. The analysis concerns both inbound and domestic overnight visitors. The sum of inbound and domestic overnight expenditure has reported a total fall of $£ 42.4$ million between 2008 Q3 and 2009 Q3. This resulted from a drop in domestic tourism expenditure receipts of $£ 184$ million but largely offset by a $£ 142$ million rise in inbound tourism receipts.

The inbound market has appeared to benefit from the depreciation of sterling. Expenditure of inbound tourists is an export, which is typically expected to react positively to a devaluation of the domestic currency. Outbound tourism, which represents an imported good, would be expected to show the opposite reaction to exchange rate depreciation and, indeed, has fallen by approximately $£ 2.3$ billion over the analysis period.

The fall in sterling also plays an indirect role through the staycation effect. As Figure 4 shows, whilst the expenditure of outbound holiday makers has shrunk, the expenditure of domestic holiday makers has increased. There is a strong possibility that this is a direct substitution from outbound travel to domestic travel. Furthermore, this is likely to be a net positive impact as the alternative to domestic holiday expenditure, in this case, is an outbound foreign trip which is a leakage from the economy.

Business tourism, as might be expected, has fallen by just over $£ 1$ billion. This is generated by a $£ 668$ million fall in inbound business expenditure, and a $£ 369$ million fall in domestic tourism. This probably reflects the cost-cutting practices of domestic and international firms in reducing their outlays on non-essential business trips.

The tourism sector, whilst benefiting from an increase in purchases of its goods, actually suffers from an overall fall in output. This result highlights how the expenditures of different types of visitors have contrasting effects in terms of the indirect effects borne by other sectors. For example, VFR visitors spend more of their income, compared to holiday and business visitors, on tourism related industries which use a higher proportion of their intermediate consumption on goods produced by the tourism sector. This is indicated by the fact that holiday and business visitors spend more on hotels than VFR visitors; the hotel industry being the one which demands the least, as a proportion of its total intermediate consumption, on the output of the tourism sector. The result being that the correlation between the direct and indirect effects of holiday and business visitors is less than that of VFR visitors.

The financial intermediation sector shows the greatest absolute indirect change over the period studied. This shows that this sector plays the greatest role in the production processes of goods that tourists purchase. To summarise, the Leontief inverse approach shows that the fall in direct tourism spending of $£ 42.4$ million has initiated a total fall in output for the economy of $£ 87 \mathrm{~m}$. A negative indirect spending effect of $£ 20.6$ million and a negative induced spending effect of $£ 24.0$ million implies an output to direct spending multiplier of 2.1 .

This article applies an input-output methodology to estimate the indirect and induced effects following a direct change in spending. This approach can be used for other scenarios, for instance, to assess the economic impact of mega-events. Further improvements to this methodology though may involve the consideration of a number of factors. Firstly, there are many recognised shortcomings of the input-output methodology, including the assumption of linear production functions ${ }^{11}$. A possible improvement might consider the use of more advanced approaches - the most obvious candidate being Computable General Equilibrium (CGE) models. Second, it would be interesting to estimate how the change in demand for a good affects the output of the industry producing that good. This would take into account factors such as VAT and the importance of imported goods. Finally, the IO framework could be linked with an employment module so the user can assess the impact of a change in final demand to a change in employment.

\section{Notes}

1. 3.3 per cent represents the demand to supply ratio reported in the UK Experimental Tourism Satellite Account (E-UKTSA) for the year 2006.

2. Authors' calculations based on the International Passenger Survey (IPS)

3. Available at www.statistics.gov.uk/ StatBase/Product.asp? vlnk $=242$

4. Available at www.statistics.gov.uk/ statbase $/$ Product.asp?vlnk $=8168$

5. The Input-Output methodology utilises the Leontief inverse framework, for which Wassily Leontief won the Nobel Prize in 1973. 
6. The tourism sector is internationally defined as a group of industries in Standard Industrial Classification coding 2007. The industries are: accommodation services, food and beverage services, transport services, travel agencies and other reservation services, cultural services, and sports and recreational services.

7. The assumption that a product is always produced by its supplying industry is not valid. Consider, for example, an agricultural industry which also produces bed and breakfast services.

8. Visits for miscellaneous purposes include those for study, to attend sporting events, for shopping, health, religious or other purposes, together with visits for more than one purpose when no one purpose predominates (such as visits both on business and on holiday). Overseas visitors staying overnight in the UK between another destination are also included in the miscellaneous purposes category.

9. UNWTO (2008), International Recommendations for Tourism Statistics

10. Hara, Tadayuki (2008), Quantitative Tourism and Industry Analysis, pp.39113

11. For further reading on this see Dwyer, Forsyth and Spurr (2003), Evaluating tourism's economic effects: new and old approaches.

\section{ACKNOWLEDGEMENTS}

The authors would like to thank Karen Turner's ESRC Leadership Fellow for providing the Input Output Tables developed from the work of the Stockholm Environment Institute. Finally, thanks to $\mathrm{Dr}$ Calvin Jones for his valuable insight and expertise.

\section{FURTHER INFORMATION}

This paper represents a first step in a wider programme of research on the economic impact of events which the Tourism Intelligence Unit (TIU) is undertaking as a result of increased interest in this issue from its stakeholder bodies, as articulated through the English Tourism Intelligence Partnership (ETIP).

\section{CONTACT}

《)elmr@ons.gov.uk 


\section{APPENDIX}

\section{Calculating the indirect impact of changes in tourists' expenditure}

\section{Inter-industry transactions}

Indirect effects occur due to inter-industry transactions in the production process. This is because the output of certain industries may represent the intermediate inputs into other industries (known as intermediate consumption), as well as final demand.

The relationship between intermediate consumption and output is summarised as:

$A X+Y=X$

This states that output, $X$, is the sum of final demand, $Y$, and the proportion, $A$, of output traded between industries as intermediate consumption.

\section{Input-Output tables}

An Input-Output table is the basic framework for recording the intermediate consumption between different industries. It is an industry-by-industry matrix recording domestic transactions for the most important industries making up the UK economy. By row, the table shows each industry's output destination. A value in an industry column represents that the row industry is selling its output to that column industry as intermediate consumption. Anything else is final demand, which is often disaggregated by purchasing agent, such as households, government or exports. The columns show the mix of intermediate consumption required to make that industry's final output. It also provides information on that industry's compensation of employees, imports, taxes and gross operating surplus - the total of which is gross value added.

The ONS regularly produces Supply and Use (SU) tables for the UK, which include a Combined Use (CU) matrix. Although similar to Input Output tables, they fail to represent information that is important to studying inter-industry transactions. By column, the CU matrix shows the input of products in the construction of industry output. By row, it shows the location of products, whether by intermediate consumption or final demand. Crucially though, it provides no information on the industry that produced the product. For instance, although the agricultural industry produces mainly agricultural products, it will also produce others, such as bed and breakfast rooms, which is considered an accommodation product. The SU table does not report this information, and hence, can not provide information on the value of interindustry transactions.

Another crucial aspect of the 10 table is that it only records inter-industry transactions for domestic industries. Imports are recorded elsewhere. This is important when analysing the links between industries. For instance, to take an earlier example, if the hotel industry imports the textiles required for linen, then further rounds of domestic spending do not occur. If the textiles are traded with a domestic industry then effects will then reach further, to other domestic industries that the textile industry trades with to produce the sheets. The CU matrix just shows the value of products used, and makes no distinction of whether the product is imported or domestically produced.

Table A1

Aggregated industry-by-industry symmetric input output matrix at basic prices, 2004

\begin{tabular}{|c|c|c|c|c|c|c|c|}
\hline Industry & Retail trade ${ }^{1}$ & $\begin{array}{l}\text { Hotels and } \\
\text { restaurants }\end{array}$ & $\begin{array}{r}\text { Financial } \\
\text { intermediation }^{2}\end{array}$ & All other products & $\begin{array}{r}\text { Total } \\
\text { intermediate } \\
\text { demand }\end{array}$ & $\begin{array}{r}\text { Total final } \\
\text { demand }\end{array}$ & $\begin{array}{r}\text { Total demand for } \\
\text { products }\end{array}$ \\
\hline Retail trade ${ }^{1}$ & 27 & 89 & 21 & 790 & 927 & 96,521 & 97,448 \\
\hline Hotels and restaurants & 847 & 302 & 115 & 2,767 & 4,031 & 65,650 & 69,681 \\
\hline Financial intermediation ${ }^{2}$ & 2,390 & 2,023 & 6,630 & 55,916 & 66,958 & 21,007 & 87,965 \\
\hline All other products & 30,649 & 31,393 & 20,083 & 752,141 & 834,267 & $1,059,729$ & $1,893,996$ \\
\hline Total intermediate consumption & 33,914 & 33,807 & 26,849 & 811,614 & & & \\
\hline Gross value added at basic prices & 60,286 & 32,233 & 56,818 & 906,758 & & & \\
\hline Imports & 3,248 & 3,641 & 4,299 & 175,623 & & & \\
\hline Gross output at basic prices & 97,448 & 69,681 & 87,965 & $1,893,996$ & & & \\
\hline
\end{tabular}

\section{Notes:}

1 Except of motor vehicles and motor cycles; repair of personal and household goods.

2 Except insurance and pension funding. 
The last IO table produced by the ONS was for the year 1995. However, the Stockholm Environment Institute (SEI) produced one for 2004. However, this is reported in a product-byproduct fashion, and is not appropriate for calculating changes in output at an industry level. As a result, they have been converted into industry-by-industry format by Karen Turner's ESRC Leadership Fellow. The drawback is the same as for the MM tables, in that it relates to data from 2004. However, according to equation (1) it is only the proportions in the table that are used and these are not expected to change much over time. Of course, the argument exists that firms in the recession might have streamlined their production, causing more efficient mixes of inputs. If that were the case, this would in fact cause the proportions to change in recent periods.

Table A1 shows a condensed version of the 10 table used, aggregating all industries into sectors. It shows that in the production of financial intermediation products, $f 5$ million of retail trade products were used as intermediate consumption. Similarly 8 per cent of hotel and restaurants products are consumed as intermediate consumption for other products, while the rest serves final demand.

Calculating change in output

Calculating the change in output from change in final demand requires manipulation of equation (1). Factoring out from the right-hand-side of the equation yields,

$Y=(I-A) X$

Where $\mathrm{I}$ is the identity matrix. Then multiplying through by the inverse of $(\mathrm{I}-\mathrm{A})$ and taking the differences yields,

$(I-A)^{-1} \Delta Y=\Delta X$

Equation (3) states that the inverse of the proportion of leftover output used for intermediate multiplied by the change in final demand equals the change in output. $(I-A)^{-1}$ is the famous Leontief inverse and provides the relationship between final demand and output. The A matrix is simply derived by dividing intermediate consumption for each industry by the output of each industry. Table $\mathbf{A} \mathbf{2}$ and Table $\mathbf{A} \mathbf{3}$ show the A matrix of Table A1, and the identity matrix respectively. -

Table A2

The 'A' matrix derived from Table A1

\begin{tabular}{|c|c|c|c|c|}
\hline Industry & Retail trade $^{1}$ & $\begin{array}{r}\text { Hotels and } \\
\text { restaurants }\end{array}$ & $\begin{array}{r}\text { Financial } \\
\text { intermediation }^{2}\end{array}$ & All other products \\
\hline Retail trade $^{1}$ & 0.00 & 0.00 & 0.00 & 0.00 \\
\hline Hotels and restaurants & 0.01 & 0.00 & 0.00 & 0.00 \\
\hline Financial intermediation ${ }^{2}$ & 0.02 & 0.03 & 0.08 & 0.03 \\
\hline All other products & 0.31 & 0.45 & 0.23 & 0.40 \\
\hline
\end{tabular}

\section{Notes:}

Source: Karen Turner's ESRC Leadership Fellow

1 Except of motor vehicles and motor cycles; repair of personal and household goods.

2 Except insurance and pension funding.

Table A3

The $4 \times 4$ Identity matrix

\begin{tabular}{|l|r|r|r|r|}
\hline & Retail trade & Hotels and \\
Industry & 1 & $\begin{array}{r}\text { Financial } \\
\text { restaurants }\end{array}$ & 0 & intermediation \\
& All other products \\
\hline Retail trade $^{1}$ & 0 & 0 & 0 \\
Hotels and restaurants $^{2}$ & 0 & 1 & 0 & 0 \\
Financial intermediation & & 0 & 1 & 0 \\
All other products & 0 & 0 & 0 & 1 \\
\hline
\end{tabular}

Notes:

Source: Authors' calculation

1 Except of motor vehicles and motor cycles; repair of personal and household goods.

2 Except insurance and pension funding. 